\title{
Synapse-Associated Protein-97 Mediates $\alpha$-Secretase ADAM10 Trafficking and Promotes Its Activity
}

\author{
Elena Marcello, ${ }^{1 \star}$ Fabrizio Gardoni, ${ }^{1 \star}$ Daniela Mauceri, ${ }^{1}$ Stefano Romorini, ${ }^{2}$ Andreas Jeromin, ${ }^{3}$ Roberta Epis, ${ }^{1}$ \\ Barbara Borroni, ${ }^{4}$ Flaminio Cattabeni, ${ }^{1}$ Carlo Sala, ${ }^{2}$ Alessandro Padovani, ${ }^{4}$ and Monica Di Luca ${ }^{1}$ \\ ${ }^{1}$ Department of Pharmacological Sciences and Centre of Excellence on Neurodegenerative Diseases, University of Milan, 20133 Milan, Italy, ${ }^{2}$ Consiglio \\ Nazionale delle Ricerche, Institute of Neuroscience, Cellular and Molecular Pharmacology, Department of Pharmacology, University of Milan, 20129 Milan, \\ Italy, ${ }^{3}$ Center for Learning and Memory, University of Texas at Austin, Austin, Texas 78712, and ${ }^{4}$ Department of Neurological Sciences, University of \\ Brescia, 25125 Brescia, Italy
}

\begin{abstract}
Alzheimer's disease (AD) is a chronic neurodegenerative disorder caused by a combination of events impairing normal neuronal function. Here we found a molecular bridge between key elements of primary and secondary pathogenic events in AD, namely the elements of the amyloid cascade and synaptic dysfunction associated with the glutamatergic system. In fact, we report that synapse-associated protein-97 (SAP97), a protein involved in dynamic trafficking of proteins to the excitatory synapse, is responsible for driving ADAM10 (a disintegrin and metalloproteinase 10, the most accredited candidate for $\alpha$-secretase) to the postsynaptic membrane, by a direct interaction through its Src homology 3 domain. NMDA receptor activation mediates this event and positively modulates $\alpha$-secretase activity. Furthermore, perturbing ADAM10/SAP97 association in vivo by cell-permeable peptides impairs ADAM10 localization in postsynaptic membranes and consequently decreases the physiological amyloid precursor protein (APP) metabolism. Our findings indicate that glutamatergic synapse activation through NMDA receptor promotes the non-amyloidogenic APP cleavage, strengthening the correlation between APP metabolism and synaptic plasticity.
\end{abstract}

Key words: ADAM10; SAP97; APP; glutamatergic synapse; Alzheimer's disease; trafficking

\section{Introduction}

Molecular pathogenesis of neurodegenerative diseases, such as Alzheimer's disease (AD), is the result of a complex interplay of several crossing pathways, involving primary and secondary events (Bossy-Wetzel et al., 2004).

In the case of $\mathrm{AD}$, accumulating evidence indicates the amyloid cascade as the primary pathogenic event (Selkoe, 2000). The production of amyloid $\beta(\mathrm{A} \beta)$ is mediated by the concerted action of two different secretases, namely $\beta$-secretase (BACE) (Vassar et al., 1999) and $\gamma$-secretase (De Strooper et al., 1998), showing a proteolytic action on the amyloid precursor protein (APP). Alternatively, APP can be subjected to the proteolytic cleavage by $\alpha$-secretase [whose most accredited candidate is ADAM10 (a disintegrin and metalloproteinase 10)] (Lammich et al., 1999; Postina et al., 2004), which occurs within the sequence of $A \beta$, thus precluding the formation of the amyloidogenic fragments. These

\footnotetext{
Received Aug. 9, 2006; revised Nov. 30, 2006; accepted Dec. 24, 2006.

This work was supported by European Community Contract LSHM-CT-2004-511995 (Synaptic Scaffolding Proteins Orchestrating Cortical Synapse Organisation during Development), Istituto di Ricovero e Cura a Carattere Scientifico Ministry of Health and Progetto Alzheimer Regione Lombardia Ministry of Health, PRIN 2005 (all to M.D.), and by Alzheimer's Organization (F.G.). We thank A. Longhi for technical assistance, L. Riccioni, and I. Squellerio and M. Malinverno for excellent practical work. We are grateful to M. Passafaro for kindly providing SAP97 CDNA, F. Fahrenholz for CDNA of ADAM10, M. Sheng for GFP-PSD-95 CDNA, and Y. Hayashi for SAP97 siRNA construct.

${ }^{*}$ E.M. and F.G. contributed equally to this work.

Correspondence should be addressed to Monica Di Luca, Department of Pharmacological Sciences, University of Milan, Via Balzaretti 9, 20133 Milan, Italy. E-mail: monica.diluca@unimi.it.

DOI:10.1523/JNEUROSCI.3439-06.2007

Copyright $\odot 2007$ Society for Neuroscience $\quad$ 0270-6474/07/271682-10\$15.00/0
}

two processes are differentially segregated within the cells, being $\alpha$-secretase activity localized in the trans-Golgi network or at the plasma membrane (Lammich et al., 1999; Gutwein et al., 2003), whereas BACE activity is mainly confined to the endoplasmic reticulum and the endosomal/lysosomal system (Kinoshita et al., 2003). Hence, the mechanism that regulates intracellular localization and trafficking to the neuronal membrane of the APP and secretases is central for $\mathrm{AD}$ pathogenesis.

Besides these processes, defined as primary pathogenic events in $\mathrm{AD}$, synaptic abnormalities involving inhibitory and excitatory neurons occurring early in the course of the disease have been described (Selkoe, 2002). Among others, the glutamatergic circuitry has been shown to be implicated in the early phases of AD, and this is reflected in a loss of synaptic plasticity (Gylys et al., 2004).

At a molecular level, the glutamatergic synapse is characterized by a complex and finely tuned network of protein-protein interactions defining both the presynaptic cytomatrix (Garner et al., 2000) and the postsynaptic density (PSD) (Kim and Sheng, 2004). The PSD is a highly organized biochemical organelle that segregates, in a highly ordered array, membrane receptors and signaling elements clustered through a family of linker proteins, i.e., the membrane associated guanylate kinase (MAGUK). MAGUKs are characterized by a common multimodular motif including three PDZ (PSD-95/Discs large/zona occludens-1) domains, an Src homology domain 3 (SH3), and a guanylate kinaselike domain (Kim and Sheng, 2004). Among MAGUKs, synapse- 
associated protein-97 (SAP97) has been described to be involved in ionotropic glutamate receptors (iGluRs) trafficking (Gardoni et al., 2003; Mauceri et al., 2004). Interestingly, in AD brains, a reduced interaction between SAP97 and GluR1 subunits of AMPA receptor has been reported, suggesting a deficiency in SAP97 functioning in AD pathogenesis (Wakabayashi et al., 1999).

Here, we asked whether there would be a molecular link between key elements of primary pathogenic events, i.e., the amyloid cascade, and of secondary pathogenic events in AD, namely synaptic loss associated to the glutamatergic system. Thus, we checked for a link between SAP97, involved in the dynamic trafficking of key elements to the excitatory postsynaptic membrane, and the elements of the amyloid cascade. The results obtained demonstrate a clear interaction between ADAM10 and SAP97 that is instrumental for the intracellular localization and the activity of $\alpha$-secretase.

\section{Materials and Methods}

Antibodies, DNA constructs, and cell-permeable peptide. The following antibodies were used: monoclonal antibody $(\mathrm{mAb}) 22 \mathrm{C} 11$ (raised against $\mathrm{N}$-terminal domain of APP), mAb 4G8 [against 17-24 amino acids (aa) of $\mathrm{A} \beta$ ], mAb anti- $\alpha$-calcium/calmodulin-dependent kinase (CaMKII), and polyclonal antibody (pAb) anti-NR2A/B were purchased from Chemicon (Temecula, CA); pAb anti-SAP97, pAb anti-SAP102, pAb anti-BACE, and $\mathrm{mAb}$ anti-PSD-95 were purchased from Affinity BioReagents (Golden, CO); mAb anti-SAP97 was from Stressgen Biotechnologies (Victoria, British Columbia, Canada); pAb anti-ADAM10 and pAb anti-actin were from Sigma (St. Louis, $\mathrm{MO}$ ); $\mathrm{mAb}$ anti-hemagglutinin (HA) and anti-synaptophysin were purchased from Roche (Mannheim, Germany); pAb APP Ab-2, raised against 1-10 aa of $A \beta$, was from Lab Vision (Fremont, CA); pAb guinea pig Shank was a gift from M. Sheng (Massachusetts Institute of Technology, Cambridge, MA); pAb antigreen fluorescent protein (GFP) and AlexaFluor 488, 555, and $633 \mathrm{sec}-$ ondary antibodies were purchased from Invitrogen (Carlsbad, CA); and peroxidase-conjugated secondary antibodies from Pierce (Rockford, IL).

The stop codon resulting in the SAP97 construct (aa 547) was introduced using the QuickChange Site-Directed Mutagenesis kit (Stratagene, La Jolla, CA), to obtain SAP97 ${ }^{547}$.

Tat-Pro ADAM10 $0^{709-729}$ peptide was obtained by linking the 11 aa human immunodeficiency virus Tat transporter sequence to the 21 aa sequence (Aarts et al., 2002) corresponding to ADAM10 proline rich domains $\left(\mathrm{NH}_{2}\right.$-YGRKKRRQRRRPKLPPPKPLPGTLKRRRPPQP$\mathrm{COOH})$, Tat-Ala ADAM10 ${ }^{709-729}$ peptide $\left(\mathrm{NH}_{2}\right.$-YGRKKRRQRRRAKLAAAKALAGTLKRRRAAQA-COOH) in which all proline residues were mutated into alanine was used as negative control. The peptides were synthesized and labeled with fluorescein at the N-terminal region by Primm (Milan, Italy).

Determination of $A \beta_{42}$ release. For the evaluation of $A \beta_{42}$ released from control (C) and treated cells into the cell media, an ELISA kit was used (Wako Pure Chemicals, Osaka, Japan). The test was performed as indicated in the instructions of the manufacturer: a standard curve ranging from 1 to $100 \mathrm{pmol} / \mathrm{L}$ was obtained with each point corresponding to the average of two measurements. The release of $\mathrm{A} \beta_{42}$ was evaluated by reference to the standard curve.

Cloning, expression, and purification of glutathione S-transferase fusion protein. SAP97 fragments or ADAM10 cytosolic tail were subcloned downstream of glutathione $S$-transferase (GST) in the BaMHI and HindIII sites of the expression plasmid pGEX-KG by PCR using the Pfu polymerase (Promega, Madison, WI). GST-fusion proteins were expressed in Escherichia coli, purified on glutathione agarose beads (Sigma) as described previously (Gardoni et al., 2001).

Cell cultures and transfection. Hippocampal neuronal cultures were prepared from embryonic day 18 (E18) to E19 rat hippocampi as described previously (Gardoni et al., 2002). Neurons were transfected using the calcium phosphate precipitation method at $10 \mathrm{~d}$ in vitro (DIV). COS-7 cells were transiently transfected by Superfect Transfection Re- agent (Qiagen, Valencia, CA) with cDNA expression constructs (1.5-2 $\mu \mathrm{g}$ of DNA per well) for $2-3 \mathrm{~h}$ at $5 \% \mathrm{CO}_{2}, 37^{\circ} \mathrm{C}$, and, afterward, cells were washed twice with PBS. COS-7 cells were grown for $24 \mathrm{~h}$ before fixation for immunocytochemistry.

Soluble APP $\alpha$ and C-terminal fragments detection. To detect soluble $\operatorname{APP} \alpha(\operatorname{sAPP} \alpha)$ released from hippocampal neurons, neuronal cultures were incubated in HBSS (Sigma), and cell media were desalted by using DG10 columns (Bio-Rad, Hercules, CA), lyophilized, resuspended in sample buffer, and analyzed by Western blot (WB) with polyclonal APP Ab-2 antibody. The evaluation of $\operatorname{sAPP} \alpha$ was achieved by loading the total lyophilisate and normalizing the optical density to the total proteins. Inhibition of ADAM10 was performed by incubation with $15 \mathrm{nM}$ tissue inhibitor of metalloproteinases-1 (TIMP-1) (Calbiochem, Nottingham, UK) for $1 \mathrm{~h}$.

To analyze APP C-terminal fragments (CTFs), Triton X-100-insoluble fractions (TIF) proteins were separated by $15 \%$ Tris-tricine SDS-PAGE, and WB analysis was performed with 4G8 antibody.

Immunofluorescence labeling, image acquisition. Hippocampal neurons or transfected COS-7 cells were fixed in $100 \%$ methanol at $-20^{\circ} \mathrm{C}$ for 15 min. Primary and secondary antibodies were applied in GDB buffer (30 $\mathrm{mm}$ phosphate buffer, $\mathrm{pH} 7.4$, containing $0.2 \%$ gelatin, $0.5 \%$ Triton $\mathrm{X}-100$, and $0.8 \mathrm{M} \mathrm{NaCl}$ ) (Sala et al., 2001). Fluorescence images were acquired using Bio-Rad Radiance 2100 confocal microscope. Confocal images were obtained using a Nikon (Tokyo, Japan) $60 \times$ objective with sequential acquisition setting at $1024 \times 1024$ pixels resolution. Each image was a $z$-series projection of $\sim 8-12$ images taken at $0.5 \mu \mathrm{m}$ depth intervals.

PSD preparation. PSD from mouse brains were purified as described previously (Gardoni et al., 2001).

Immunoprecipitation. Aliquots of either Tat-ProADAM10 ${ }^{709-729}$ peptide or Tat-Ala ADAM10 ${ }^{709-729}$ peptide $(10 \mu \mathrm{M}, 2 \mathrm{~h})$ treated neurons homogenate, human cortex homogenate, mouse brain homogenate, or PSD were incubated in RIA buffer $(200 \mathrm{~mm} \mathrm{NaCl}, 10 \mathrm{~mm}$ EDTA, $10 \mathrm{~mm}$ $\mathrm{Na}_{2} \mathrm{HPO}_{4}, 0.5 \% \mathrm{NP}-40$, and $0.1 \%$ SDS) in a final volume of $200 \mu \mathrm{l}$ with antibody against ADAM10 (Sigma) overnight at $4^{\circ} \mathrm{C}$. Protein A-agarose beads were added, and incubation was continued for $2 \mathrm{~h}$, at room temperature, with shaking. The beads were washed three times with RIA buffer. Sample buffer for SDS-PAGE was added, and the mixture was heated for $3 \mathrm{~min}$. Beads were collected by centrifugation, and a volume of supernatants was applied onto 6\% SDS-PAGE; immunocomplex precipitation was revealed by monoclonal anti-SAP97, polyclonal anti-SAP102, or $\mathrm{pAb}$ anti-NR2A/B antibodies.

Pull-down assay. Aliquots of PSD were diluted with TBS (10 mm Tris and $150 \mathrm{~mm} \mathrm{NaCl}$ ) and $0.1 \%$ SDS to a final volume of $1 \mathrm{ml}$ and incubated $\left(1 \mathrm{~h}, 37^{\circ} \mathrm{C}\right)$ with glutathione agarose beads saturated with fusion proteins or GST alone. After the incubation period, the beads were extensively washed with TBS and $0.1 \%$ Triton X-100. Bound proteins were resolved by SDS-PAGE and subjected to immunoblot analysis with polyclonal anti-SAP97 or ADAM10 antibodies.

Neuronal cultures treatment, TIF preparation, and surface expression assay. Hippocampal neuronal cultures at 14 DIV were incubated in HBSS (Sigma) in the presence or absence of $50 \mu \mathrm{M}$ NMDA (Sigma). Cell viability was evaluated immediately after the treatment by the 3-(4,5dimethyl-thiazol-2-yl)-2,5-diphenyltetrazolium bromide (MTT) assay, as described previously (Gardoni et al., 2002). TIFs were isolated from neurons as described previously (Gardoni et al., 2001). Cross-linking experiments by means of bis(sulfosuccinimidyl) suberate $\left(\mathrm{BS}^{3}\right)$ (Pierce) were performed as described previously (Hall and Soderling, 1997; Mauceri et al., 2004).

Lentiviral vectors preparation. For the small interfering RNA (siRNA) expressing lentivirus vector, an RNA interference stem loop (Nakagawa et al., 2004) has been cloned in the lentivirus-based vector pLL3.7 (Massachusetts Institute of Technology Center for Cancer Research, Cambridge, MA) (Rubinson et al., 2003), and an empty pLL3.7 vector has been used to generate the control lentivirus vectors. The ubiquitin promoter was replaced with the synapsin promoter. The lentiviral infecting particles were prepared as described previously (Lois et al., 2002). Neurons were infected with SAP97 siRNA (SAP97i) lentivirus at 6 DIV, and TIF preparation was performed at 10 DIV. 
A

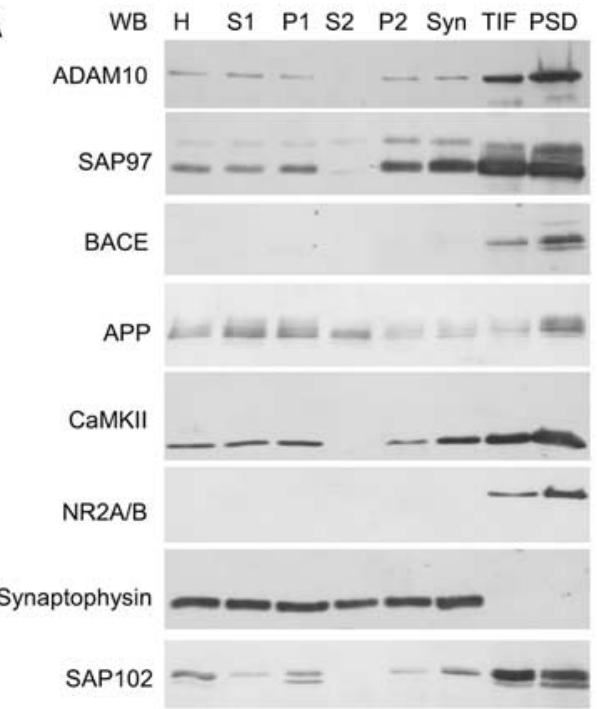

B
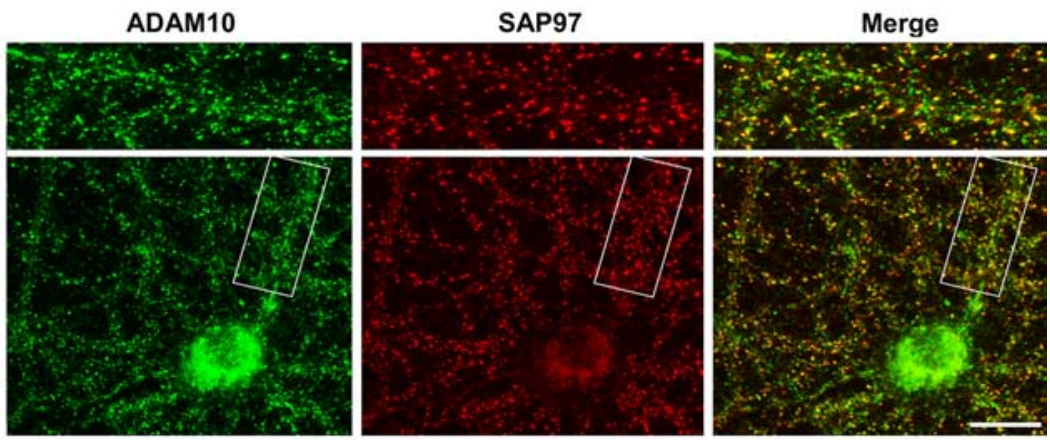

ADAM10
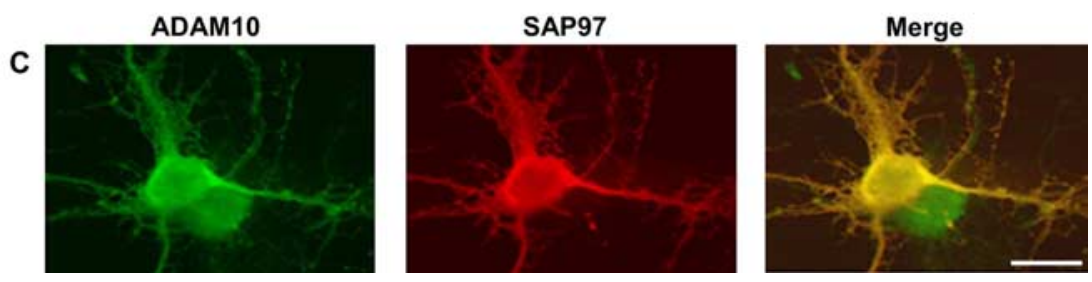

Figure 1. SAP97 and ADAM10 colocalize in PSD purified from mouse brain and in primary hippocampal neurons. A, SAP97, ADAM10, BACE, and APP as well as markers of the presynaptic compartment (synaptophysin) and postsynaptic side (CaMKII, NR2A/B) and another member of MAGUK family (SAP102) in various subcellular compartments were analyzed by means of WB. $H$, Homogenate; $\mathrm{S1}$, low-speed supernatant; P1, nuclei-associated membranes; $S 2$, high-speed supernatant; $\mathrm{P2}$, crude membrane fraction; Syn, synaptosomes. $\boldsymbol{B}, 14$ DIV hippocampal neurons were immunolabeled for ADAM10 (left) and SAP97 (middle). Merged images are shown at the right. Scale bar, $10 \mu \mathrm{m}$. Representative dendrites are shown at higher magnification. C, Hippocampal neurons were transfected with wild-type SAP97, fixed, and stained for endogenous ADAM10 (green) and transfected SAP97 (red). SAP97 overexpression leads to ADAM10 diffuse distribution toward cell soma and dendrites, with a high colocalization degree. Merged image is shown on the right. Scale bars, $10 \mu \mathrm{m}$.

Animal treatment. Adult C57BL/6 mice were obtained from Charles River (Calco, Italy) and received a single intraperitoneal injection of either Tat-Pro ADAM10 ${ }^{709-729}$ peptide or Tat-Ala ADAM10 ${ }^{709-729}$ peptide $(3 \mathrm{nmol} / \mathrm{g})$ diluted in sterile saline or vehicle alone. Animals were killed $24 \mathrm{~h}$ after injection, and the brain was rapidly dissected.

Brains of control and treated mice were fixed in $4 \%$ paraformaldehyde in $0.1 \mathrm{~m}$ phosphate buffer, $\mathrm{pH} 7.4$ (on ice), and, after $24 \mathrm{~h}$, in $30 \%$ sucrose in $0.1 \mathrm{M}$ phosphate buffer, $\mathrm{pH}$ 7.4. The brain was embedded and frozen in OCT (VWR International, West Chester, PA), and sections (50 $\mu \mathrm{m}$ ) were cut on a cryostat and analyzed by fluorescence confocal microscopy.

TIF fractions were purified from one hemisphere of each either control or treated mouse, whereas the other hemisphere was homogenized by Potter homogenizer (Teflon/glass, $700 \mathrm{rpm}$ ) in HEPES/ 25 mм Na, containing 2 mM EDTA, 1 mm EGTA, and $0.1 \mathrm{~mm}$ phenylmethylsulfonyl fluoride, $\mathrm{pH}$ 7.4. Homogenates were centrifuged at $1000 \times \mathrm{g}$ for $10 \mathrm{~min}$ to remove crude nuclear material, and supernatants were further centrifuged $(60 \mathrm{~min}$ at $100,000 \times \mathrm{g}$ ). Final supernatants were used to measure soluble APP (Caputi et al., 1997). Quantification of immunostaining is shown as fold of control animals in the same experiment. Values are means \pm SEM for three independent experiments for a total of 18 animals.

All experimental procedures were performed with care to minimize discomfort and pain to treated animals, in accordance with the guidelines of the European Communities Council (Directive of November 24, 1986, 86/609/EEC).

Quantification and statistical analysis. Colocalization analysis was performed using Laserpix software (Bio-Rad). Quantification of WB analysis was performed by means of computer-assisted imaging (QuantityOne System; Bio-Rad), and statistical evaluations were performed according to paired Student's $t$ test or one-way ANOVA, when appropriate, followed by Bonferroni's as a post hoc test. Values are shown as means \pm SEM.

\section{Results}

\section{SAP97 colocalizes with ADAM10 in hippocampal neurons}

The distribution pattern of SAP97 and key elements of the amyloid cascade (APP, BACE, and ADAM10) was investigated using a biochemical fractionation approach (Fig. $1 A$ ). PSDs were puri- fied from mouse brain tissue, and SAP97 as well as APP, BACE, and ADAM10 enrichment into different subcellular compartments was analyzed. ADAM10 displayed a high colocalization degree, with SAP97 being enriched in isolated PSD and showing a similar pattern of distribution in the different subcellular fractions (Fig. 1A). Even if both APP and BACE were detected in the postsynaptic compartment, distribution pattern into the different subcellular fractions was not comparable with that of SAP97 (Fig. 1A).

Immunocytochemical labeling of ADAM10 in 14 DIV cultured hippocampal neurons revealed a diffuse somatodendritic staining pattern in hippocampal neurons (Fig. $1 \mathrm{~B}$, bottom row). Careful examination of dendritic ADAM10 staining showed a high colocalization degree with SAP97 in a punctuate "spinelike" structures (Fig. $1 B$, top rows). Conversely, no visible colocalization of both APP (data not shown) and BACE (data not shown) with SAP97 was observed.

High colocalization degree between SAP97 and ADAM10 was further confirmed in hippocampal neurons transfected with wild-type SAP97, fixed, and stained for endogenous ADAM10 and transfected SAP97 (Fig. 1C).

To investigate the localization of ADAM10 at either side of the synapse, we double labeled neurons for ADAM10 and PSD-95 (Fig. 2A, a marker of postsynaptic structures) or synaptophysin (Fig. $2 \mathrm{~B}$, a marker of presynaptic compartment). ADAM10 colocalized with PSD-95 but not with synaptophysin, indicating the presence of ADAM10 at the postsynaptic side of excitatory synapses. Furthermore, triple staining of neurons with ADAM10, SAP97, and Shank (a marker of postsynaptic structures) confirm the colocalization between ADAM10 and SAP97 in the postsynaptic compartment (Fig. 2C).

\section{SAP97 interacts with ADAM10 through the SH3 domain}

The possible interaction between ADAM10 and SAP97 was investigated by means of coimmunoprecipitation experiments. 

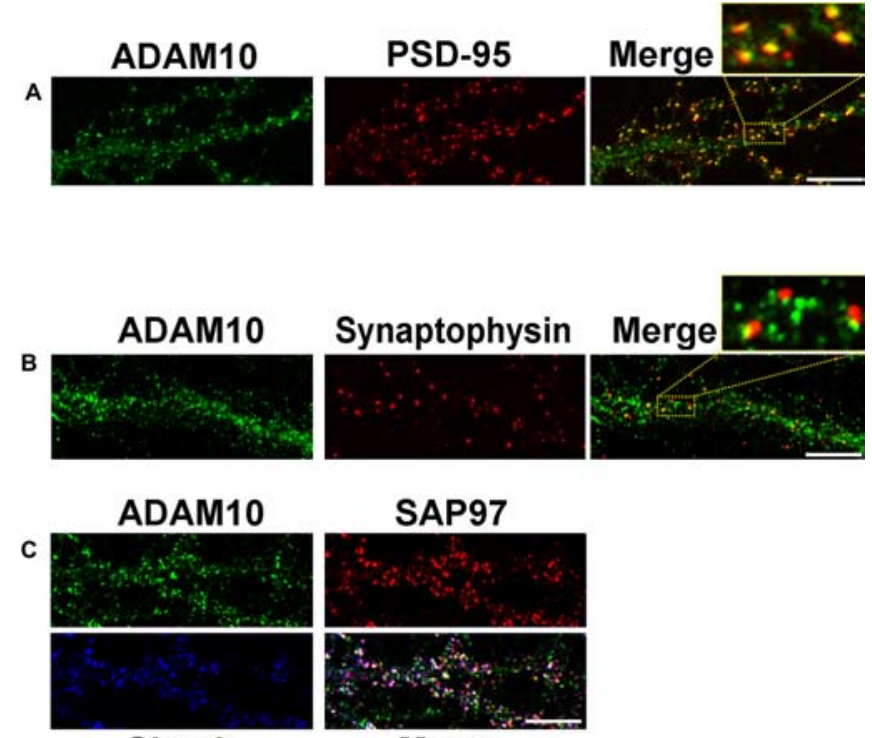

Shank

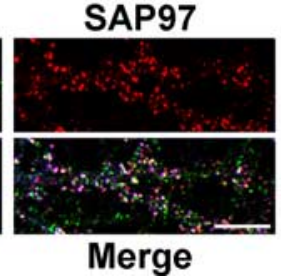

Figure 2. $\quad \boldsymbol{A}, \mathrm{ADAM} 10$ (green) and PSD-95 (red) staining in dendritic compartment. Merged images are shown on the right. Top, High-magnification images indicating ADAM10/PSD-95 colocalization at postsynaptic sites. Scale bar, $4 \mu \mathrm{m}$. B, ADAM10 (green) and synaptophysin (red) staining in dendritic compartment; merged images are shown on the right; top, highmagnification images. Scale bar, $4 \mu \mathrm{m}$. C, ADAM10 (green), SAP97 (red), and Shank (blue) staining in dendritic compartment. Scale bar, $4 \mu \mathrm{m}$.

SAP97 coprecipitated with ADAM10 in both homogenate and purified PSD fractions from brain tissue (Fig. $3 A$, left column). In addition, a similar ADAM10-SAP97 interaction has been found in coimmunoprecipitation assay performed from human cortex homogenate (Fig. 3A, right column).

To check for specificity, we evaluated a possible interaction between ADAM10 and SAP102, another member of the MAGUK family, showing the highest degree of sequence homology with SAP97. No signal corresponding to SAP102 was detectable in the immunocomplex in either homogenate or PSD fraction, indicating that SAP102 is not able to interact with ADAM10 (Fig. 3A). Moreover, the absence of any NR2A/B signal in ADAM10 coimmunoprecipitates excludes that in our experimental conditions the coprecipitation of SAP97 reflects an unspecific immunoprecipitation (Fig. 3A) (Gardoni et al., 2003).

We then evaluated the possibility of a direct interaction between SAP97 and ADAM10. Analysis of the amino acidic sequence of ADAM10 and SAP97 revealed the presence of two proline-rich domains in ADAM10 cytoplasmic tail, essential for ADAM10 sorting (Wild-Bode et al., 2006), which could interact with the SH3 domain of SAP97. To test this hypothesis, we used a pull-down approach. Fusion proteins of GST with SAP97-SH3(580-650), SAP97-PDZ1-(217-318), SAP97-PDZ3-(465$545)$, and SAP97-N-terminal domain-(7-223) were purified and incubated with PSD proteins. GST-SAP97-SH3-(580-650) was solely able to pull down ADAM10, and neither GST alone nor the other SAP97 domains tested interacted with ADAM10 (Fig. 3B, top).

To further confirm these results, solubilized PSD proteins were incubated with GST-ADAM10-(697-748) containing the two proline-rich sequences and submitted to pull-down experiments. Western blot analysis revealed a band corresponding to SAP97, indicating that ADAM10 cytoplasmic tail directly binds SAP97 (Fig. 3B, bottom). This set of experiments demonstrated a direct interaction between SAP97 and ADAM10 occurring through $\mathrm{SH} 3$ and proline-rich domains.

To support these findings in intact living cells, we performed a clustering assay in heterologous cells. COS-7 cells were double transfected with ADAM10 and SAP97; both proteins showed a diffuse distribution throughout the cell with the presence of clusters in which ADAM10 immunoreactivity colocalized with SAP97 (Fig. 3C). In contrast, cotransfection of ADAM10 with GFP-PSD-95 or with SAP97 deletion construct SAP97 ${ }^{547}$, lacking the $\mathrm{SH} 3$ domain, showed a perinuclear accumulation of ADAM10 (Fig. 3C) comparable with the staining observed in ADAM10 single transfection (data not shown). Therefore, ADAM10 proline stretches are responsible for interaction with SAP97 SH3 domain.

\section{SAP97 drives ADAM10 to spines on NMDA receptor activation} Is ADAM10/SAP97 interaction relevant in influencing the localization of the enzyme inside the cell?

SAP97 has been implicated in the synaptic targeting of ionotropic glutamate receptor subunits (Gardoni et al., 2003; Mauceri et al., 2004). NMDA receptor activation is known to be sufficient to drive SAP97 to the PSD in cultured neurons (Gardoni et al., 2003); hence, we asked whether the same experimental conditions are capable of delivering also ADAM10 to this compartment.

Hippocampal neurons were incubated in the absence or presence of NMDA ( $50 \mu \mathrm{M}, 1 \mathrm{~h})$, and then ADAM10 trafficking to the postsynaptic membrane was analyzed. TIF, which is enriched in PSD proteins (Gardoni et al., 2001), was obtained from control and NMDA-treated neurons, and protein levels measured by Western blotting. NMDA treatment significantly increased both SAP97 (Fig. $4 A)(n=9 ; p=0.037 ;+73.4 \pm 29.3 \%$, NMDA vs C) and ADAM10 immunostaining (Fig. $4 A)(n=9 ; p=0.021$; $+73.8 \pm 26.6 \%$, NMDA vs C) in the TIF, without affecting the levels of the two proteins in the homogenate (Fig. $4 A)(n=9 ; p>$ 0.05 , ADAM10 and SAP97 NMDA vs C). As a negative control, CaMKII levels were not modified by the NMDA treatment (Fig. 4A) ( $n=9 ; p>0.05$, NMDA vs C). Thus, NMDA receptor activation affects the redistribution of ADAM10/SAP97 within the cell.

Biochemical data were further confirmed by immunocytochemical labeling of ADAM10 in cultured hippocampal neurons; as shown in Figure $4 B$, NMDA treatment led to an increased punctuate staining of ADAM10 in spine-like structures and to a concomitant decrease of ADAM10 signal along the dendritic shafts (Fig. $4 B)\left(F_{\text {spines }} / F_{\text {dendrites }}, n=40 ; C, 0.962 \pm 0.061\right.$; NMDA, $1.325 \pm 0.074 ; p=0.810^{-3}$, NMDA vs C).

In parallel samples, cell viability by means of MTT test was checked ( $n=9 ; p>0.05$, NMDA vs $C$ ), which excluded NMDAdependent cell death in our experimental conditions.

We next examined the effects of NMDA treatment on ADAM10 surface expression. To this, control and NMDA hippocampal cultures were treated with the cross-linker $\mathrm{BS}^{3}$, a membrane-impermeable amine-reactive cross-linker reagent (Fig. 4C). ADAM10 surface pool was not detectable because of the formation of high-molecular-weight aggregates that barely entered the gel (Fig. 4C, top). Whereas no alteration of a cytosolic protein such as actin was detected, a significant decrease in the ADAM10 intracellular pool was observed (Fig. $4 C)(n=3 ; p=$ $0.031 ;-31 \pm 5.6 \%$, NMDA vs C), indicating that NMDA receptor activation promotes ADAM10 insertion in the cell membranes. 
ADAM10/SAP97 association positively modulates ADAM10 activity

The enzymatically active form of ADAM10 mainly exerts its effect of $\alpha$-secretase cleavage of APP in the membrane compartment (Lammich et al., 1999). Thus, the functional consequences of SAP97-mediated trafficking of ADAM10 on ADAM10 activity and APP processing products were further investigated in hippocampal neuronal cultures after NMDA treatment. In these experimental conditions, both sAPP $\alpha$ release in the medium and APP CTFs, CTF99 for $\beta$-cleavage and CTF83 for $\alpha$-cleavage, respectively (Kamenetz et al., 2003; Zimmermann et al., 2004; Adlard et al., 2005), were measured. Immunoblot experiments, performed with pAb APP Ab-2, raised against $1-10$ amino acids of the $A \beta$ sequence, showed that NMDA treatment increased sAPP $\alpha$ release from hippocampal neurons (Fig. $4 D$, left) $(n=9 ; p=$ $0.04 ;+81.1 \pm 35.8 \%$, NMDA vs C). sAPP $\alpha$ release from hippocampal neurons is suggested to be attributable to ADAM10 activity because TIMP-1, an inhibitor of metalloproteinases (Amour et al., 2000; Brew et al., 2000), completely blocked sAPP $\alpha$ release (Fig. $4 D$, right). $\mathrm{A} \beta_{42}$ release was measured by ELISA, and the results obtained show that NMDA treatment significantly reduces $\mathrm{A} \beta_{42}$ secretion in neuronal medium $(n=4 ; p=0.006$; $-32.1 \pm 4.6 \%$, NMDA vs C).

TIF proteins from control and treated neurons were then separated by $15 \%$ Tristricine gel and subjected to Western blot analysis with mAb 4G8 to detect both CTF99 and CTF83. Quantitative analysis revealed that NMDA treatment determined a significant increase of CTF83/CTF99 ratio (Fig. $4 E)(n=9 ; p=$ $0.015 ;+17.8 \pm 5.8 \%$, NMDA vs C), again indicating an enhancement of $\alpha$-secretase activity. Therefore, NMDA receptor activation under physiological conditions induces ADAM10 trafficking, through association with SAP97, toward postsynaptic membranes and in turn enables APP cleavage at the $\alpha$-secretase site.

Interaction with SAP97 is needed for ADAM10 trafficking to postsynaptic compartment

To further clarify the role of SAP97 in the modulation of ADAM10 targeting to the postsynaptic membranes, a fluorescein labeled cell-penetrating Tat peptide (Green and Loewenstein, 1988 ) fused to ADAM10 proline-rich domains (Tat-Pro ADAM10 ${ }^{709-729}$ ) was used to disrupt ADAM10/SAP97 interaction. Peptide penetration into hippocampal neurons was first assessed by means of confocal microscopy (data not shown). Second, Tat-Pro ADAM10 ${ }^{709-729}(10 \mu \mathrm{M})$ capability of interfering with ADAM10/SAP97 association in primary cultures was evaluated by coimmunoprecipitation experiments after 2 or $6 \mathrm{~h}$ of peptide treatment (Fig. 5A). Treatments with Tat-Ala ADAM10 ${ }^{709-729}$ peptide (in which all proline residues were substituted with alanine) were always performed as control.

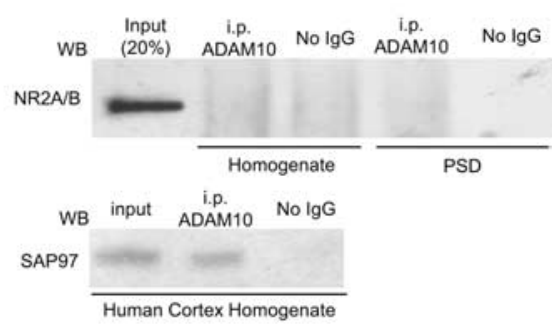

C
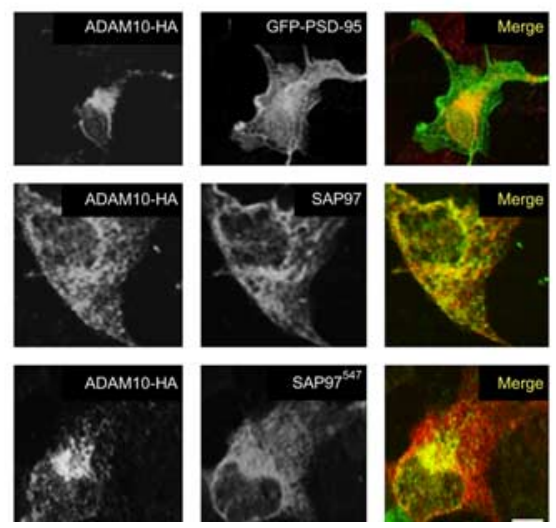

Figure 3. SAP97 directly interacts with ADAM10 through its SH3 domain, which recognizes proline-rich motifs in ADAM10

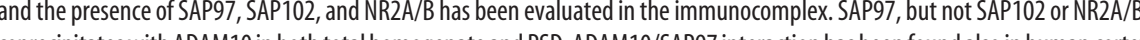
a truncated form of SAP97 lacking SH3 and guanylate kinase domains. Cells were fixed and labeled with pAb anti-SAP97, pAb anti-GFP, and $\mathrm{mAb}$ anti-HA. Scale bar, $10 \mu \mathrm{m}$.

Tat-Pro ADAM10 ${ }^{709-729}$ peptide was able to disrupt ADAM10/SAP97 interaction already after $2 \mathrm{~h}$ of incubation (Fig. $5 A$ ) and proved this approach useful to verify SAP97 role in driving ADAM10 to the postsynaptic membrane. As expected, no effect on ADAM10/SAP97 interaction was induced by the TatAla ADAM10 ${ }^{709-729}$ peptide (Fig. $5 B$ ).

Cultures exposed or not exposed to Tat-Pro ADAM10 ${ }^{709-729}$ peptide were then treated with NMDA $(50 \mu \mathrm{M}, 1 \mathrm{~h})$ and double labeled for ADAM10 and PSD-95. Confocal microscopy showed that Tat-Pro ADAM10 ${ }^{709-729}$ peptide incubation per se was not able to induce modifications of ADAM10 immunostaining, whereas NMDA treatment alone led to an increased punctuate staining of ADAM10 in spine-like structures (Fig. 5C), confirming the above described data (Fig. $4 A, B$ ). Quantification of ADAM10 staining revealed a significant increase in ADAM10 colocalization with PSD-95 as a marker for spine structure (Fig. $5 D)(n=47 ; p=0.048$, NMDA vs C). Conversely, when neuronal cultures were preincubated with Tat-Pro ADAM10 ${ }^{709-729}$ peptide, NMDA receptor activation failed to induce the increase of ADAM10 staining in spine-like structures (Fig. 5D) $(n=47$; $p=0.03$; NMDA plus Tat-Pro ADAM10 $0^{709-729}$ vs NMDA). Therefore, the cell-permeable peptide, which interferes with ADAM10/SAP97 association, is able to prevent NMDA-induced ADAM10 trafficking to the postsynaptic compartment. No effect on ADAM10 localization in PSD-95-positive spine-like structure 
A

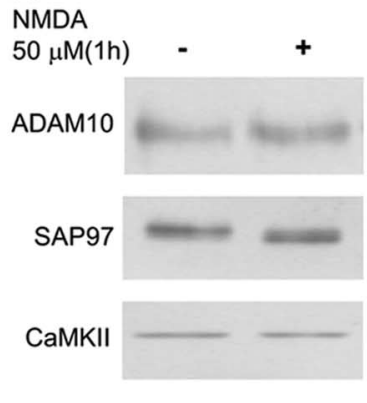

Homo

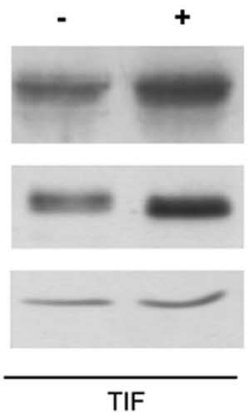

B

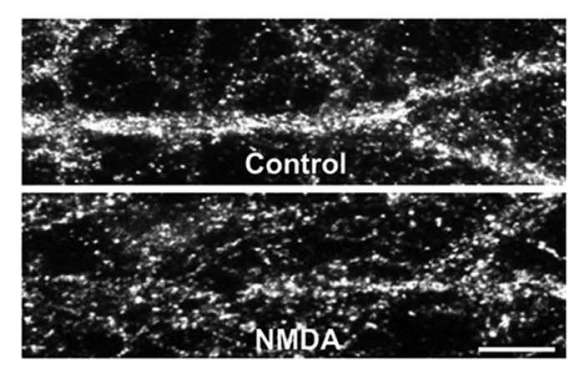

D

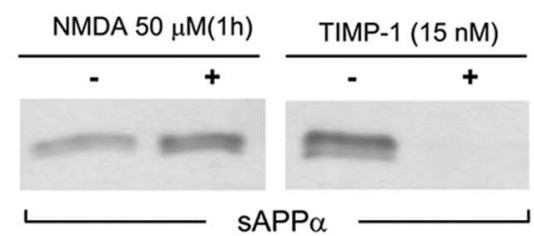

C

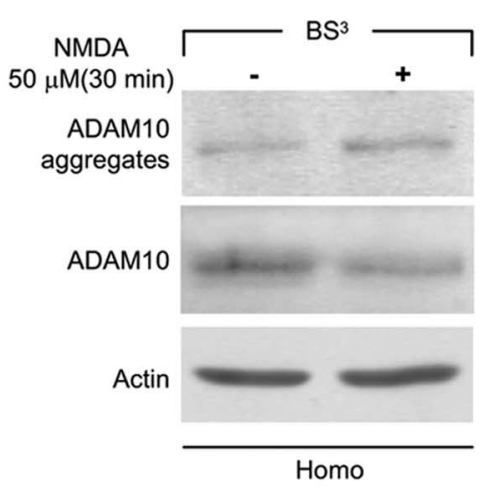

$E$

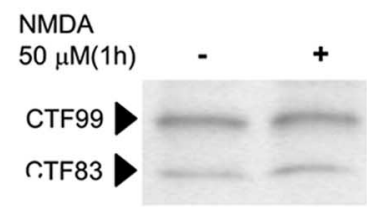

Figure 4. NMDA receptor activation induces ADAM10 trafficking toward the postsynaptic membranes. $\boldsymbol{A}$, WB analysis of homogenate and TIF obtained from control or NMDA-treated high-density hippocampal cultures. NMDA treatment $(50 \mu \mathrm{M}, 1 \mathrm{~h})$ leads to a redistribution of SAP97 and ADAM10 in TIF fraction but not in homogenate. $\boldsymbol{B}$, Control and NMDA (50 $\mu \mathrm{M}, 1 \mathrm{~h})$-treated hippocampal cultures were fixed and immunostained for ADAM10, and the ratio of spines to dendrites average fluorescence was computed and averaged. Scale bar, $4 \mu \mathrm{m}$. C, WB of ADAM10 and actin from control and NMDA (50 $\mu \mathrm{m}, 30 \mathrm{~min}$ )-treated hippocampal cultures exposed to the cross-linker BS ${ }^{3}$. NMDA treatment increases ADAM10 surface expression, because a significant decrease of ADAM10 intracellular pool is observed. ADAM10 high-molecular-weight complexes that barely entered the gel are shown in the top. $D$, WB analysis of SAPP $\alpha$ released from control and TIMP-1 (15 nM, $1 \mathrm{~h}$ )-treated hippocampal neuronal cultures. SAPP $\alpha$ secretion from hippocampal neurons was attributable to ADAM10 activity, because TIMP-1 blocked sAPP $\alpha$ release. NMDA treatment $(50 \mu \mathrm{m}, 1 \mathrm{~h})$ increases SAPP $\alpha$ secretion in primary hippocampal cultures. Immunoblots were performed with the polyclonal Ab-2 antibody, which reacts specifically with sAPP $\alpha$. $\boldsymbol{E}$, NMDA receptor activation enhances CTF83/CTF99 ratio in hippocampal neurons. TIF proteins were separated by $15 \%$ Tris-tricine gel, and APP CTFs were revealed by immunoblotting with $4 \mathrm{G} 8$ antibody.

was induced by treatment with Tat-Ala ADAM10 ${ }^{709-729}$ control peptide (Fig. $5 D)(n=47 ; p=0.0001$, NMDA plus Tat-Pro ADAM10 ${ }^{709-729}$ vs NMDA plus Tat-Ala ADAM10 ${ }^{709-729}$ ).

To evaluate the effect on APP metabolism, cultures exposed or not exposed to Tat-Pro ADAM10 ${ }^{709-729}$ or Tat-Ala ADAM10 ${ }^{709-729}$ peptide were then treated with NMDA $(50 \mu \mathrm{M}$, $1 \mathrm{~h}$ ), and $\mathrm{A} \beta_{42}$ release in the media was measured by ELISA. Treatment with NMDA/Tat-Pro ADAM10 ${ }^{709-729}$ peptide markedly increases the amount of $\mathrm{A} \beta_{42}$ released into the medium (Fig. 5E) $(n=3 ; p=0.00015 ;+65.9 \pm 4.7 \%$, NMDA/Tat-Pro ADAM10 ${ }^{709-729}$ vs C), suggesting that disruption of the ADAM10/SAP97 complex entails a decreased ADAM10 activity and a shift toward amyloidogenic APP metabolism. As expected, the NMDA/Tat-Ala ADAM10 ${ }^{709-729}$ treatment does not differ from NMDA alone (Fig. $5 E)(n=3 ; p=0.038 ;-25.2 \pm 7.5 \%$, NMDA plus Tat-Ala ADAM10 ${ }^{709-729}$ vs C).

\section{Effect of SAP97 siRNA on ADAM10 localization and APP metabolism}

To further evaluate the role of SAP97 in the modulation of ADAM10 function in hippocampal neurons, primary cultures were infected with SAP97i expressing lentivirus. Nearly $100 \%$ of neurons in culture can be infected with lentivirus with minimal cytotoxicity; the effect of SAP97i could therefore be quantified at a biochemical level across the entire population of neurons in culture. Compared with empty virus infection at the same viral titer, lentivirus expressing SAP97i caused profound and specific knockdown of SAP97 as shown by immunoblotting of total homogenate of hippocampal cultures. No alterations of ADAM10 or SAP102 and CaMKII as control protein levels were observed in total lysates, confirming the specificity of SAP97i knockdown (Fig. $6 A)$. TIFs were obtained from hippocampal neurons infected with either empty lentivirus or SAP97i lentivirus, and protein levels were measured by Western blotting. siRNA knockdown of SAP97 decreases ADAM10 localization in the postsynaptic compartment (Fig. 6A) $(n=$ $3 ; p=0.032 ;-50.7 \pm 9.3 \%$, SAP97i vs empty). A similar reduction is observed in SAP97 protein level in the TIFs. Again, no significant alteration of SAP102 and CaMKII levels were found (Fig. 6A).

TIF proteins from control and SAP97i neurons were then analyzed to detect both CTF99 and CTF83. Quantitative analysis revealed that siRNA knockdown of SAP97 determined a significant decrease of the CTF83/CTF99 ratio (Fig. $6 B)(n=3 ; p=$ $0.032 ;-26 \pm 4.7 \%$, SAP97i vs empty).

\section{ADAM10/SAP97 interaction affects $\alpha$ - secretase activity in vivo}

To determine whether the alteration of ADAM10/SAP97 interaction might affect ADAM10-mediated APP metabolism also in vivo, C57BL/6 mice were injected with the Tat-Pro ADAM10 ${ }^{709-729}$ peptide or with the Tat-Ala ADAM10 ${ }^{709-729}$ control peptide. Indeed, both Tat-ADAM10 ${ }^{709-729}$ peptides are able to cross the blood-brain barrier and penetrate neurons within $24 \mathrm{~h}$ after intraperitoneal injection (Aarts et al., 2002) (data not shown).

No effect of Tat peptides was detected in Western blotting performed from the whole-brain homogenate, indicating that the peptides did not affect ADAM10 as well as SAP97 expression (Fig. $7 A$, left $)\left(n=18 ; p>0.05\right.$, Tat-Pro ADAM10 ${ }^{709-729}$ peptide vs C). The interference of Tat-Pro ADAM10 ${ }^{709-729}$ with ADAM10/SAP97 association in vivo was assessed by means of coimmunoprecipitation experiments performed on brain homogenates. These experiments revealed that the administration of the peptide reduced ADAM10/SAP97 coprecipitation in treated animals compared with control mice (Fig. $7 A$, right) $(n=$ $18 ; p=0.002 ;-67.4 \pm 7.0 \%$, Tat-Pro ADAM10 ${ }^{709-729}$ peptide vs $\mathrm{C})$. As shown in the cultures above, no effect on ADAM10 interaction with SAP97 was induced by the Tat-Ala ADAM10 ${ }^{709-729}$ peptide (Fig. $7 A$, right $)(n=18 ; p>0.05$, TatAla ADAM10 ${ }^{709-729}$ peptide vs C).

In addition, we purified TIF from control, Tat-Pro 
ADAM10 10 and Tat-Ala ADAM10 ${ }^{709-729}$ peptide-treated mice. Tat-Pro ADAM10 ${ }^{709-729}$ but not Tat-Ala ADAM10 $0^{709-729}$ peptide treatment significantly reduced ADAM10 immunostaining in TIF (Fig. $7 B)(n=18 ; p=0.0003$; $-28.8 \pm 4.2 \%$, Tat-Pro ADAM10 ${ }^{709-729}$ peptide vs C). Finally, because Tat-Pro ADAM10 ${ }^{709-729}$ peptide proved to be effective in vivo, we investigated ADAM10 activity, measuring total sAPP and $\operatorname{sAPP} \alpha$ in control and treated mice brains. Western blot experiments showed that the TatPro ADAM10 ${ }^{709-729}$ but not Tat-Ala ADAM10 ${ }^{709-729}$ peptide decreased sAPP $\alpha$ production (Fig. $7 C)(n=18 ; p=0.008$; $-38.3 \pm 5.4 \%$, Tat-Pro ADAM10 ${ }^{709-729}$ peptide vs $\mathrm{C}$ ) without affecting the release of total soluble APP, indicating a reduction of ADAM10 activity (Fig. $7 C)(n=$ $18 ; p>0.05)$.

\section{Discussion}

In the last few years, a number of observations have reported a close relationship between cognitive impairment and synaptic failure within cortex and hippocampus of AD patients (DeKosky and Scheff, 1990; Bertoni-Freddari et al., 1996). Furthermore, data obtained in AD brains and APP transgenic mice revealed that synaptic dysfunction is an early event preceding physical deterioration of neuronal structures (Oddo et al., 2003; Palop et al., 2003). Although deficits in numerous neurotransmitters accrue as the disease progresses, the early symptoms appear to correlate with dysfunction of cholinergic and glutamatergic synapses (Selkoe, 2002).

In addition, although a clear dysfunction of nerve terminal has been reported (Hsia et al., 1999), preferential loss of postsynaptic compared with presynaptic elements in $\mathrm{AD}$ has been suggested based on decreases in drebrin, a postsynaptic actin-binding protein (Harigaya et al., 1996; Shim and Lubec, 2002). Neverthe-

less, a clear-cut relationship between postsynaptic elements and players of APP metabolism is not yet understood.

Here we report that a key element responsible for the correct assembly of the glutamatergic synapses, SAP97, which works as a cargo protein involved in trafficking iGluRs to the postsynaptic density (Gardoni et al., 2003; Mauceri et al., 2004), is also responsible for driving ADAM10 to the membrane. This event is primed by NMDA receptor activation, and it is mandatory for ADAM10 activity.

Recently, our laboratory demonstrated that drugs active on the cholinergic system, and used as therapy for dementia, are capable of inducing ADAM10 trafficking from the reticulum to the plasma membrane in a cholinergic receptor-independent manner (Zimmermann et al., 2004).

These results highlighted the importance of intracellular ADAM10 ${ }^{709-729}$ vs (). i.p.

ADAM10

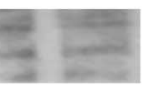

$\stackrel{+}{+} \quad \stackrel{+}{h} \quad 6 h$
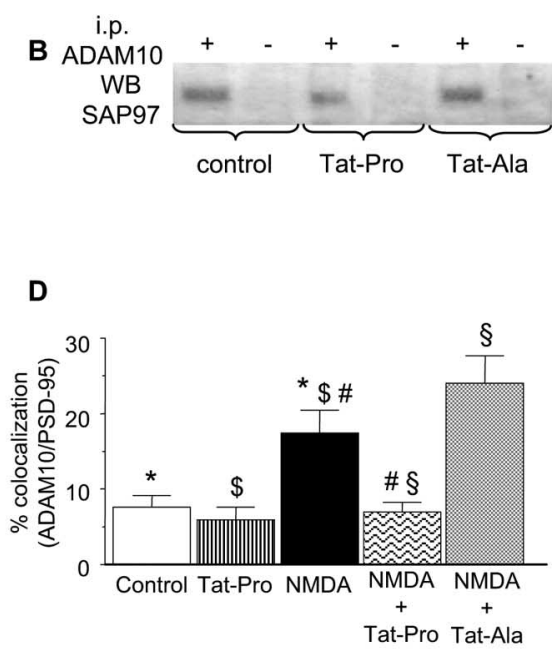

E

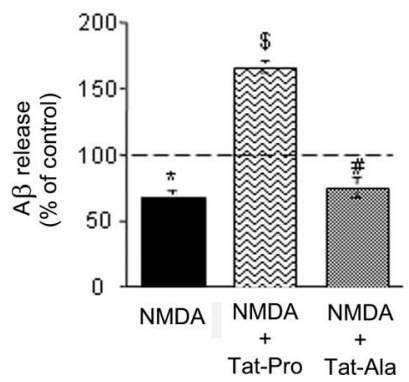

Figure 5. Interaction with SAP97 is needed for ADAM10 trafficking to postsynaptic compartment. A, Primary hippocampal cultures were exposed to Tat-Pro ADAM10 ${ }^{709-729}(10 \mu \mathrm{M})$ for 2 or $6 \mathrm{~h}$; after treatment, cell lysates were immunoprecipitated (i.p.) with ADAM10 antibody, and WB analysis was performed with SAP97 antibody. Tat-Pro ADAM10 ${ }^{709-729}$ peptide is able to disrupt tes were immunoprecipitated with ADAM10 antibody. WB analysis reveals that Tat-Pro ADAM10 ${ }^{709-729}$ peptide, but not peptide, interferes with ADAM10/SAP97 interaction. C, Representative dendrites of hippocampal neu-

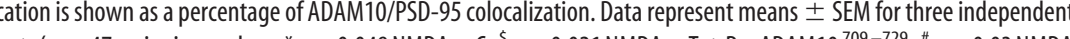
experiments $\left(n=47\right.$; pairwise $p$ values, ${ }^{*} p=0.048$ NMDA vs $C ;{ }^{\$} p=0.021$ NMDA vs Tat-Pro ADAM $10{ }^{709-729} ;{ }^{*} p=0.03$ NMDA plus Tat-Pro ADAM10 ${ }^{709-729}$ vs NMDA; ${ }^{\S} p=0.0001$ NMDA plus Tat-Pro ADAM10 ${ }^{709-729}$ vs NMDA plus Tat-Ala ADAM10 ${ }^{709-729}$ spine-like clusters, whereas Tat-Pro ADAM10 ${ }^{709-729}$ peptide, but not Tat-Ala ADAM10 ${ }^{709-729}$ peptide, preincubation pre-

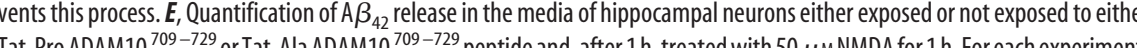
quantification is shown as fold of the appropriate control. Data represent means $+S E M$ for three independent experiments $\left(n=3 ;{ }^{*} p=0.0056\right.$ NMDA vs $C ;{ }^{\$} p=0.00015$ NMDA plus Tat-Pro ADAM10 ${ }^{709-729}$ vs $C ;{ }^{*} p=0.038$, NMDA plus Tat-Ala

ADAM10 transport as a possible key process in shifting APP processing toward the non-amyloidogenic pathway. In fact, it is well known that ADAM10 can cleave APP in the $\alpha$-secretase site only when the two proteins colocalize in either the plasma membrane or the late secretory vesicles (Lammich et al., 1999).

Even if potential $\alpha$-secretase activity has been ascribed recently to other members of the ADAM family (Buxbaum et al., 1998) and BACE2 (Yan et al., 2001; Fluhrer et al., 2002), here we show that exposure of hippocampal neurons to TIMP-1 (Amour et al., 2000; Brew et al., 2000) totally abolished sAPP $\alpha$ release. These data suggest that $\alpha$-secretase cleavage of APP in our experimental conditions can be ascribed to ADAM10.

Here we fully characterize the intracellular molecular events driving ADAM10 to the membrane in glutamatergic neurons. Indeed, SAP97 colocalizes in primary hippocampal neurons with 


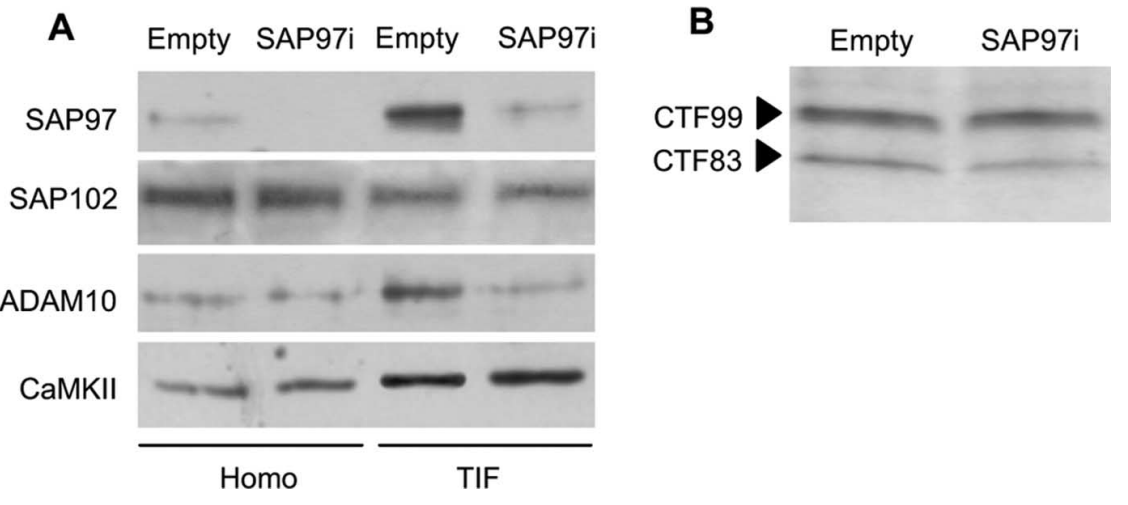

Figure 6. Effect of SAP97 siRNA on ADAM10 localization and APP metabolism. A, siRNA knockdown of SAP97 decreases ADAM10 in postsynaptic compartment. Representative immunoblot for SAP97, SAP102, ADAM10, and CaMKII in total homogenate (Homo) and TIF of hippocampal neurons infected with control (empty) lentivirus or lentivirus expressing siRNA against SAP97 (SAP97i). B, siRNA knockdown of SAP97 decreases (TF83/CTF99 ratio in hippocampal neurons infected with lentivirus expressing SAP97i compared with neurons infected with control (empty) lentivirus. TIF proteins were separated by $15 \%$ Tris-tricine gel, and APP CTFs were revealed by immunoblotting with $4 \mathrm{G} 8$ antibody.
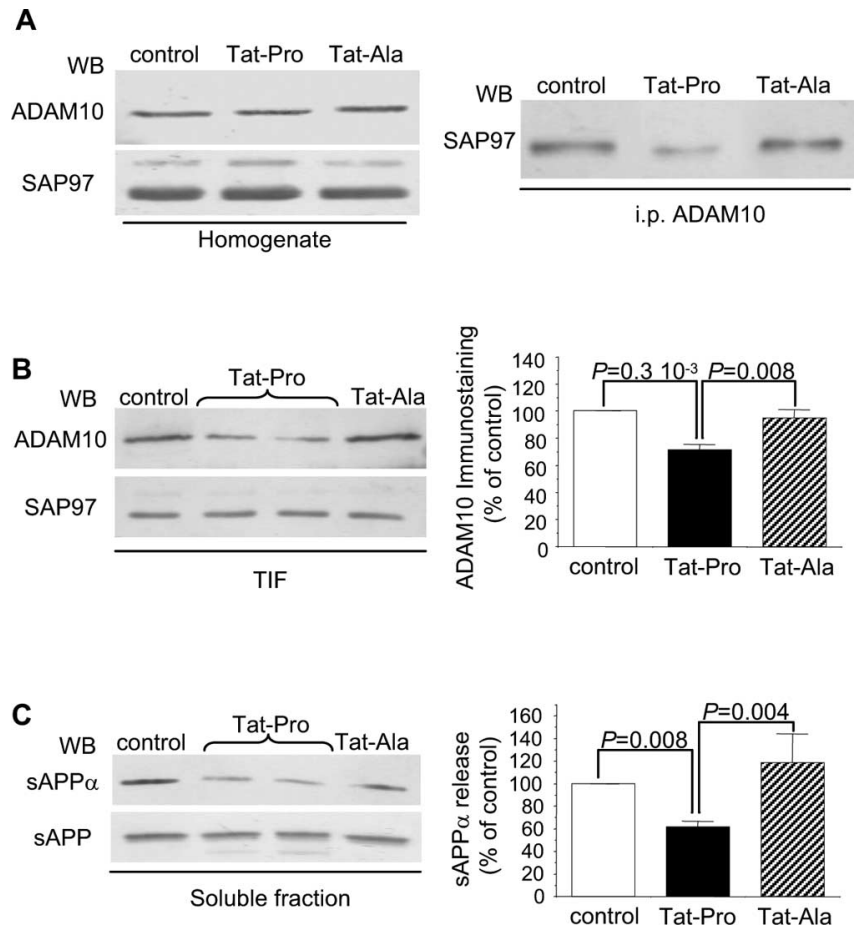

Figure 7. ADAM10/SAP97 interaction affects $\alpha$-secretase activity in vivo. A, C57BL/6 mice were intraperitoneally injected with either Tat-Pro ADAM10 ${ }^{709-729}$ or Tat-Ala ADAM10 $0^{709-729}$ peptides. ADAM10 and SAP97 protein levels in total brain homogenate are not affected by the treatment (left). Brain homogenates from control and treated mice were immunoprecipitated with ADAM10 antibody, and the immunocomplex was probed for SAP97. Tat-Pro ADAM10 ${ }^{709-729}$ peptide, but not Tat-Ala ADAM10 ${ }^{709-729}$ peptide, is able to disrupt ADAM10/ SAP97 association within $24 \mathrm{~h}$ after intraperitoneal injection (right). $\boldsymbol{B}$, WB analysis of TIF obtained from control, Tat-Pro ADAM10 ${ }^{709-729}$, and Tat-Ala ADAM10 ${ }^{709-729}$ peptide treated mice performed with anti-ADAM10 and anti-SAP97 antibodies. The treatment decreases ADAM10 level in TIF, without affecting SAP97. Quantitative analysis of immunostaining is shown as fold of control animals in the same experiment $(n=18$; pairwise $p$ values, $p=$ $0.3 \times 10^{-3},-28.8 \pm 4.2 \%$, Tat-Pro ADAM10 ${ }^{709-729}$ peptide vs $C ; p=0.008$ Tat-Pro ADAM10 ${ }^{709-729}$ peptide vs Tat-Ala ADAM10 ${ }^{709-729}$ peptide; one-way ANOVA, followed by Bonferroni's as a post hoc comparison test). C, WB analysis performed on the soluble fraction, obtained from brain of control Tat-Pro ADAM10 $0^{709-729}$ and Tat-Ala ADAM10 ${ }^{709-729}$ peptidetreated mice. SAPP $\alpha$ was revealed with the polyclonal Ab-2 antibody, whereas SAPP was detected with monoclonal $22 \mathrm{C} 11$ antibody. Quantitative analysis of immunostaining is shown as fold of control animals in the same experiment $(n=18$; pairwise $p$ values, $p=0.008,-38.3 \pm 5.4 \%$, Tat-Pro ADAM10 $0^{709-729}$ peptide vs $C ; p=0.004$ Tat-Pro ADAM10 ${ }^{709-729}$ peptide vs Tat-Ala ADAM10 $0^{709-729}$ peptide; one-way ANOVA, followed by Bonferroni's as a post hoc comparison test).
ADAM10. The colocalization of the two proteins is further strengthened by immunoprecipitation experiments, because the immunoprecipitation performed with an antibody recognizing ADAM10 entails the precipitation of SAP97 in rodent brain homogenate, in purified PSD fraction, and in human cortex.

These results not only suggest a possible direct interaction in specific subcellular domains between ADAM10 and SAP97 but they also limit the colocalization of the two proteins in a specific fraction of the postsynaptic compartment, namely the PSD. Previous studies described APP processing as a presynaptic phenomenon (Marquez-Sterling et al., 1997; Lazarov et al., 2005). Nevertheless, APP has been also located by light and electron microscopy in the PSD (Shigematsu and McGeer, 1992). Furthermore, ADAM10 has been described to shed several substrates with a postsynaptic localization (Reiss et al., 2005), and a trans-synaptic cleavage exerted by ADAM10 has been claimed recently (Janes et al., 2005).

The PSD, a membrane specialization in which receptors and signaling molecules are segregated, plays a key role in tuning the response of the postsynaptic neurons to different stimuli (Kim and Sheng, 2004). Because it is responsible for modulating the calcium response through NMDA receptor in time and space, it may be considered a locus to express both plasticity and excitotoxicity (Sattler and Tymianski, 2001). The localization of ADAM10 to the PSD, in which it expresses its function, correlates APP metabolism and iGluRs function. This relationship between iGluRs and APP metabolism may be interpreted as bidirectional given the recent findings of a direct action of soluble/oligomeric $\mathrm{A} \beta$ on the postsynaptic membrane (Cleary et al., 2005).

A pulse of NMDA, which leads to postsynaptic activation with no neuronal death, is capable of driving both SAP97 and ADAM10 to the membrane and the translocation of the enzyme in the membrane compartment is necessary and instrumental for $\alpha$-secretase activity. Interestingly, the same protocol of activation of ADAM10 has been used recently to promote the cleavage of $\mathrm{N}$-cadherin (Reiss et al., 2005).

These data reinforce the evidence of a correlation between sAPP $\alpha$ production and synaptic plasticity; in fact, $\operatorname{sAPP} \alpha$ is neuroprotective and neurotrophic and regulates cell excitability and synaptic plasticity, whereas $A \beta$ appears to exert opposite effects (Turner et al., 2003).

The trafficking of ADAM10/SAP97 induced by NMDA occurs through a direct interaction between the proline-rich domains of ADAM10 and the SH3 domain of SAP97. Furthermore, this interaction is necessary for the NMDA-induced ADAM10 trafficking, because the treatment of hippocampal neurons with the cellpermeable Tat-Pro ADAM10 ${ }^{709-729}$ peptide mimicking the proline-rich region of ADAM10 and disrupting SAP97/ADAM10 interaction counteracts the capability of NMDA of fostering SAP97/ADAM10 complex to the membrane and of promoting ADAM10 activity. Thus, ADAM10/SAP97 interaction positively modulates APP metabolism toward non-amyloidogenic processing. Interestingly, a disturbance of SAP97/GluR1 interaction has been reported in AD brain (Wakabayashi et al., 1999), suggesting a defect in trafficking and functioning of SAP97 in the course of the disease. In agreement with this finding, perturbing ADAM10/ 
SAP97 interaction in vivo leads to a shifting of APP metabolism toward amyloidogenic products. In fact, a single intraperitoneal injection of Tat-Pro ADAM10 ${ }^{709-729}$ peptide in mice led to a disruption of ADAM10/SAP97 interaction in vivo, a loss of membrane localization of ADAM10, and a strong decrease in $\alpha$-secretase activity as revealed by a reduction of $\operatorname{sAPP} \alpha$ formation in brain-soluble fraction of treated mice. These data imply that a loss of interaction between SAP97 and ADAM10 causes a strong impairment in physiological APP metabolism. Whether this mechanism entails a disturbance in the structural organization and the function of the glutamatergic synapse has still to be demonstrated, even if it is generally accepted that this synaptic circuitry is a target for toxic action of $\mathrm{A} \beta$ oligomers, in which they inhibit (Walsh et al., 2002; Wang et al., 2002) and disrupt normal expression of a synaptic immediate early gene essential for longterm memory formation (Lacor et al., 2004).

Recently, a close relationship between $\mathrm{A} \beta$ production and NMDA receptor activity in cultured neurons has been put forward (Snyder et al., 2005). Here we demonstrate that the glutamatergic synapse can intrinsically express a mechanism, driven by NMDA activation, at a postsynaptic level, that is responsible for shifting APP metabolism toward a non-amyloidogenic pathway. Thus, this represents a potential intrinsic additional mechanism of regulation of pathogenesis eventually driven by $\mathrm{A} \beta$. According to this view, the presynaptic failure and the postsynaptic induced APP metabolism may equally contribute to express $\mathrm{AD}$ pathogenesis.

Finally, our data indicate SAP97 as a bridge between key elements of the primary pathogenic events of AD, such as ADAM10, and key elements of the secondary pathogenic events such, as the glutamatergic synaptic dysfunction, adding new pieces to the puzzle in the understanding of the complex and coordinated events leading to $\mathrm{AD}$ pathogenesis.

\section{References}

Aarts M, Liu Y, Liu L, Besshoh S, Arundine M, Gurd JW, Wang YT, Salter MW, Tymianski M (2002) Treatment of ischemic brain damage by perturbing NMDA receptor- PSD-95 protein interactions. Science 298:846-850.

Adlard PA, Perreau VM, Pop V, Cotman CW (2005) Voluntary exercise decreases amyloid load in a transgenic model of Alzheimer's disease. J Neurosci 25:4217-4221.

Amour A, Knight CG, Webster A, Slocombe PM, Stephens PE, Knauper V, Docherty AJ, Murphy G (2000) The in vitro activity of ADAM-10 is inhibited by TIMP-1 and TIMP-3. FEBS Lett 473:275-279.

Bertoni-Freddari C, Fattoretti P, Casoli T, Caselli U, Meier-Ruge W (1996) Deterioration threshold of synaptic morphology in aging and senile dementia of Alzheimer's type. Anal Quant Cytol Histol 18:209-213.

Bossy-Wetzel E, Schwarzenbacher R, Lipton SA (2004) Molecular pathways to neurodegeneration. Nat Med [Suppl] 10:S2-S9.

Brew K, Dinakarpandian D, Nagase H (2000) Tissue inhibitors of metalloproteinases: evolution, structure and function. Biochim Biophys Acta 1477:267-283.

Buxbaum JD, Liu KN, Luo Y, Slack JL, Stocking KL, Peschon JJ, Johnson RS, Castner BJ, Cerretti DP, Black RA (1998) Evidence that tumor necrosis factor alpha converting enzyme is involved in regulated alpha-secretase cleavage of the Alzheimer amyloid protein precursor. J Biol Chem 273:27765-27767.

Caputi A, Barindelli S, Pastorino L, Cimino M, Buxbaum JD, Cattabeni F, Di Luca M (1997) Increased secretion of the amino-terminal fragment of amyloid precursor protein in brains of rats with a constitutive upregulation of protein kinase C. J Neurochem 68:2523-2529.

Cleary JP, Walsh DM, Hofmeister JJ, Shankar GM, Kuskowski MA, Selkoe DJ, Ashe KH (2005) Natural oligomers of the amyloid-beta protein specifically disrupt cognitive function. Nat Neurosci 8:79-84.

DeKosky ST, Scheff SW (1990) Synapse loss in frontal cortex biopsies in
Alzheimer's disease: correlation with cognitive severity. Ann Neurol 27:457-464.

De Strooper B, Saftig P, Craessaerts K, Vanderstichele H, Guhde G, Annaert W, Von Figura K, Van Leuven F (1998) Deficiency of presenilin-1 inhibits the normal cleavage of amyloid precursor protein. Nature 391:387-390.

Fluhrer R, Capell A, Westmeyer G, Willem M, Hartung B, Condron MM, Teplow DB, Haass C, Walter J (2002) A non-amyloidogenic function of BACE-2 in the secretory pathway. J Neurochem 81:1011-1020.

Gardoni F, Schrama LH, Kamal A, Gispen WH, Cattabeni F, Di Luca M (2001) Hippocampal synaptic plasticity involves competition between $\mathrm{Ca}^{2+} /$ calmodulin-dependent protein kinase II and postsynaptic density 95 for binding to the NR2A subunit of the NMDA receptor. J Neurosci 21:1501-1509.

Gardoni F, Bellone C, Viviani B, Marinovich M, Meli E, PellegriniGiampietro DE, Cattabeni F, Di Luca M (2002) Lack of PSD-95 drives hippocampal neuronal cell death through activation of an alpha CaMKII transduction pathway. Eur J Neurosci 16:777-786.

Gardoni F, Mauceri D, Fiorentini C, Bellone C, Missale C, Cattabeni F, Di Luca M (2003) CaMKII-dependent phosphorylation regulates SAP97/ NR2A interaction. J Biol Chem 278:44745-44752.

Garner CC, Kindler S, Gundelfinger ED (2000) Molecular determinants of presynaptic active zones. Curr Opin Neurobiol 10:321-327.

Green M, Loewenstein PM (1988) Autonomous functional domains of chemically synthesized human immunodeficiency virus tat transactivator protein. Cell 55:1179-1188.

Gutwein P, Mechtersheimer S, Riedle S, Stoeck A, Gast D, Joumaa S, Zentgraf H, Fogel M, Altevogt DP (2003) ADAM10-mediated cleavage of L1 adhesion molecule at the cell surface and in released membrane vesicles. FASEB J 17:292-294.

Gylys KH, Fein JA, Yang F, Wiley DJ, Miller CA, Cole GM (2004) Synaptic changes in Alzheimer's disease: increased amyloid-beta and gliosis in surviving terminals is accompanied by decreased PSD-95 fluorescence. Am J Pathol 165:1809-1817.

Hall RA, Soderling TR (1997) Quantitation of AMPA receptor surface expression in cultured hippocampal neurons. Neuroscience 78:361-371.

Harigaya Y, Shoji M, Shirao T, Hirai S (1996) Disappearance of actinbinding protein, drebrin, from hippocampal synapses in Alzheimer's disease. J Neurosci Res 43:87-92.

Hsia AY, Masliah E, McConlogue L, Yu GQ, Tatsuno G, Hu K, Kholodenko D, Malenka RC, Nicoll RA, Mucke L (1999) Plaque-independent disruption of neural circuits in Alzheimer's disease mouse models. Proc Natl Acad Sci USA 96:3228-3233.

Janes PW, Saha N, Barton WA, Kolev MV, Wimmer-Kleikamp SH, Nievergall E, Blobel CP, Himanen JP, Lackmann M, Nikolov DB (2005) Adam meets Eph: an ADAM substrate recognition module acts as a molecular switch for ephrin cleavage in trans. Cell 123:291-304.

Kamenetz F, Tomita T, Hsieh H, Seabrook G, Borchelt D, Iwatsubo T, Sisodia S, Malinow R (2003) APP processing and synaptic function. Neuron 37:925-937.

Kim E, Sheng M (2004) PDZ domain proteins of synapses. Nat Rev Neurosci 5:771-781.

Kinoshita A, Fukumoto H, Shah T, Whelan CM, Irizarry MC, Hyman BT (2003) Demonstration by FRET of BACE interaction with the amyloid precursor protein at the cell surface and in early endosomes. J Cell Sci 116:3339-3346.

Lacor PN, Buniel MC, Chang L, Fernandez SJ, Gong Y, Viola KL, Lambert MP, Velasco PT, Bigio EH, Finch CE, Krafft GA, Klein WL (2004) Synaptic targeting by Alzheimer's-related amyloid beta oligomers. J Neurosci 24:10191-10200.

Lammich S, Kojro E, Postina R, Gilbert S, Pfeiffer R, Jasionowski M, Haass C, Fahrenholz F (1999) Constitutive and regulated alpha-secretase cleavage of Alzheimer's amyloid precursor protein by a disintegrin metalloprotease. Proc Natl Acad Sci USA 96:3922-3927.

Lazarov O, Morfini GA, Lee EB, Farah MH, Szodorai A, DeBoer SR, Koliatsos VE, Kins S, Lee VM, Wong PC, Price DL, Brady ST, Sisodia SS (2005) Axonal transport, amyloid precursor protein, kinesin-1, and the processing apparatus: revisited. J Neurosci 25:2386-2395.

Lois C, Hong EJ, Pease S, Brown EJ, Baltimore D (2002) Germline transmission and tissue-specific expression of transgenes delivered by lentiviral vectors. Science 295:868-872.

Marquez-Sterling NR, Lo AC, Sisodia SS, Koo EH (1997) Trafficking of 
cell-surface $\beta$-amyloid precursor protein: evidence that a sorting intermediate participates in synaptic vesicle recycling. J Neurosci 17:140-151.

Mauceri D, Cattabeni F, Di Luca M, Gardoni F (2004) Calcium/ calmodulin-dependent protein kinase II phosphorylation drives synapseassociated protein 97 into spines. J Biol Chem 279:23813-23821.

Nakagawa T, Futai K, Lashuel HA, Lo I, Okamoto K, Walz T, Hayashi Y, Sheng M (2004) Quaternary structure, protein dynamics, and synaptic function of SAP97 controlled by L27 domain interactions. Neuron 44:453-467.

Oddo S, Caccamo A, Shepherd JD, Murphy MP, Golde TE, Kayed R, Metherate R, Mattson MP, Akbari Y, LaFerla FM (2003) Triple-transgenic model of Alzheimer's disease with plaques and tangles: intracellular Abeta and synaptic dysfunction. Neuron 39:409-421.

Palop JJ, Jones B, Kekonius L, Chin J, Yu GQ, Raber J, Masliah E, Mucke L (2003) Neuronal depletion of calcium-dependent proteins in the dentate gyrus is tightly linked to Alzheimer's disease-related cognitive deficits. Proc Natl Acad Sci USA 100:9572-9577.

Postina R, Schroeder A, Dewachter I, Bohl J, Schmitt U, Kojro E, Prinzen C, Endres K, Hiemke C, Blessing M, Flamez P, Dequenne A, Godaux E, van Leuven F, Fahrenholz F (2004) A disintegrin-metalloproteinase prevents amyloid plaque formation and hippocampal defects in an Alzheimer disease mouse model. J Clin Invest 113:1456-1464.

Reiss K, Maretzky T, Ludwig A, Tousseyn T, de Strooper B, Hartmann D, Saftig P (2005) ADAM10 cleavage of N-cadherin and regulation of cellcell adhesion and beta-catenin nuclear signalling. EMBO J 24:742-752.

Rubinson DA, Dillon CP, Kwiatkowski AV, Sievers C, Yang L, Kopinja J, Rooney DL, Ihrig MM, McManus MT, Gertler FB, Scott ML, Van Parijs L (2003) A lentivirus-based system to functionally silence genes in primary mammalian cells, stem cells and transgenic mice by RNA interference. Nat Genet 33:401-406.

Sala C, Piech V, Wilson NR, Passafaro M, Liu G, Sheng M (2001) Regulation of dendritic spine morphology and synaptic function by Shank and Homer. Neuron 31:115-130.

Sattler R, Tymianski M (2001) Molecular mechanisms of glutamate receptor-mediated excitotoxic neuronal cell death. Mol Neurobiol 24:107-129.

Selkoe DJ (2000) Toward a comprehensive theory for Alzheimer's disease. Hypothesis: Alzheimer's disease is caused by the cerebral accumulation and cytotoxicity of amyloid beta-protein. Ann NY Acad Sci 924:17-25.
Selkoe DJ (2002) Alzheimer's disease is a synaptic failure. Science 298:789-791.

Shigematsu K, McGeer PL (1992) Accumulation of amyloid precursor protein in neurons after intraventricular injection of colchicine. Am J Pathol 140:787-794.

Shim KS, Lubec G (2002) Drebrin, a dendritic spine protein, is manifold decreased in brains of patients with Alzheimer's disease and Down syndrome. Neurosci Lett 324:209-212.

Snyder EM, Nong Y, Almeida CG, Paul S, Moran T, Choi EY, Nairn AC, Salter MW, Lombroso PJ, Gouras GK, Greengard P (2005) Regulation of NMDA receptor trafficking by amyloid-beta. Nat Neurosci 8:1051-1058.

Turner PR, O'Connor K, Tate WP, Abraham WC (2003) Roles of amyloid precursor protein and its fragments in regulating neural activity, plasticity and memory. Prog Neurobiol 70:1-32.

Vassar R, Bennett BD, Babu-Khan S, Kahn S, Mendiaz EA, Denis P, Teplow DB, Ross S, Amarante P, Loeloff R, Luo Y, Fisher S, Fuller J, Edenson S, Lile J, Jarosinski MA, Biere AL, Curran E, Burgess T, Louis JC, et al. (1999) Beta-secretase cleavage of Alzheimer's amyloid precursor protein by the transmembrane aspartic protease BACE. Science 286:735-741.

Wakabayashi K, Narisawa-Saito M, Iwakura Y, Arai T, Ikeda K, Takahashi H, Nawa H (1999) Phenotypic down-regulation of glutamate receptor subunit GluR1 in Alzheimer's disease. Neurobiol Aging 20:287-295.

Walsh DM, Klyubin I, Fadeeva JV, Cullen WK, Anwyl R, Wolfe MS, Rowan MJ, Selkoe DJ (2002) Naturally secreted oligomers of amyloid beta protein potently inhibit hippocampal long-term potentiation in vivo. Nature 416:535-539.

Wang HW, Pasternak JF, Kuo H, Ristic H, Lambert MP, Chromy B, Viola KL, Klein WL, Stine WB, Krafft GA, Trommer BL (2002) Soluble oligomers of beta amyloid (1-42) inhibit long-term potentiation but not long-term depression in rat dentate gyrus. Brain Res 924:133-140.

Wild-Bode C, Fellerer K, Kugler J, Haass C, Capell A (2006) A basolateral sorting signal directs ADAM10 to adherens junctions and is required for its function in cell migration. J Biol Chem 281:23824-23829.

Yan R, Munzner JB, Shuck ME, Bienkowski MJ (2001) BACE2 functions as an alternative alpha-secretase in cells. J Biol Chem 276:34019-34027.

Zimmermann M, Gardoni F, Marcello E, Colciaghi F, Borroni B, Padovani A, Cattabeni F, Di Luca M (2004) Acetylcholinesterase inhibitors increase ADAM10 activity by promoting its trafficking in neuroblastoma cell lines. J Neurochem 90:1489-1499. 